\title{
Evaluation and Simulation on the Reserve Capacity of Thermal Storage Electric Boiler Clusters
}

\author{
Linjun Cai ${ }^{1}$, Zheng Zhang ${ }^{1}$, Dongliang Xie ${ }^{1}$, Xiaofang Song $^{1}$, Yening Lai ${ }^{1}$ \\ 1. NARI Group Corporation /State Grid Electric Power Research Institute, 211106 Nanjing, China
}

\begin{abstract}
After providing a better service for nearby heating loads, a thermal storage electric boiler system can use the heat storage tank to participate in the peak-shaving and reserve services of the power grid. Current researches focus on its peak-shaving capacity, but ignores the use of its reserve capacity, which is important to the random fluctuations of renewable energy sources. Facing the actual analyzing demands on power system adequacy, this paper starts with the discussion of typical operation modes, and builds the powersystem-adequacy model of a thermal-storage electric boiler based heating system. Based on the presented model, the concept of feasible domain for heat charging and discharging is proposed. By implementing the concept, the quantitative evaluation method to calculate the reserve capacity of a thermal storage electric boiler system is proposed. The verification of the method is also given. Based on the planning data of an actual power grid, the short-term reserve capacity as well as the effect on promoting renewable energy consumption is estimated according to the given size of the provincial thermal storage electric boiler clusters. Finally, the influences of different choices of peak-shaving strategies, heat storage tank capacity on its reserve capacity are simulated and analyzed.
\end{abstract}

\section{Introduction}

The transformation to clean, low-carbon energy [1] is the inevitable trend of energy development in the world, the large-scale, high-proportion grid-connection of wind power generation/PV power generation brings more obvious power balance pressure for the power grid, and there are obvious power balance problems in "Three Norths"'(Northeast China North China, Northwest China) which are located in the transmission end of the grid [2-3]. The power supply and heat supply restrict each other during the heating period in winter. "Fixing heat based on power" restricts the flexible adjustment (depth peak regulation and reserve) ability of electrical power system which relies mainly on thermal power, and exacerbates the seasonal "three curtailments" (wind curtailment, PV power generation curtailment, and water curtailment) phenomena. The "three curtailments" can be effectively relieved through improving the flexibility of power grid and strengthening the synergy of energy /grid /load /storage.

The dispatching department pays more attention to thermal storage [5-8], which is a potential energy storage regulation means of power generation side and demand side. Utilizing the limited thermal storage capacity of electric boiler itself; Equipping large electric boilers for thermal power plant can strengthen the coal saving effect of through thermoelectric decoupling [9]; Adding the peak regulation electric boiler in the secondary heat supply network can effectively decrease the wind curtailment, and reduce the coal consumption [10]. However, the role of the thermal storage device cannot be played fully, because the volume of electric boiler is limited, and the thermoelectric decoupling is not thorough.

Thermoelectric decoupling thermal storage electric boiler realizes the deeply decoupling of power supply and heat supply through equipping the thermal storage tank for electric boiler. The literature analyzes the consumption and wind curtailment mechanism of thermal storage electric boiler, and discusses the influencing factors of consumption ability from the aspects of boiler configuration, thermal storage capacity, thermal storage and release strategy, etc. The literature[12] puts forward the operation strategy of racking the wind curtailment power for the energy-storage coordinated thermal storage electric boiler, which can realize the active consumption and wind curtailment while guaranteeing the heat supply. The literature [13] further researches the optimization configuration method of thermal storage electric boiler for consumption and wind curtailment, and develops the optimal planning platform. The literature [14] focuses on the assistance towards the market environment for the development of thermal storage electric boiler, puts forward a wind curtailment electricity price bidding mechanism of multiple wind fields, which can reduce the electricity purchasing cost of the thermal storage electric boiler system.

The improvement of boiler thermal storage capacity is not only beneficial to the deep involvement in power grid peak regulation, but also provides reserve capacity, while

\footnotetext{
${ }^{*}$ Corresponding author: cailinjun@sgepri.sgcc.com.cn
} 
the latter has been less involved in the existing researches. As a rotating reserve resource for demand side [15], the thermal storage electric boiler can not only provide the upregulation reserve (the electric power of electric boiler is decreased, the heat is output by thermal storage tank instead of the boiler), but also provide down-regulation reserve (the electric power of electric boiler is increased, the redundant heat output is stored in the thermal storage tank). The ability of the thermal storage electric boiler for involving in operation reserve is related to electric power of boiler, thermal storage and release power of thermal storage tank, thermal storage capacity of thermal storage tank, thermal load power, current thermal storage capacity, time period of thermal storage and release and other factors, and it changes over time.

This paper models power adequacy characteristic of heating system for thermal storage electric boiler on the basis of comparing the operation mode of boiler heating systems with thermal storage capacity and that without thermal storage capacity. After the mechanism analysis using the model, this paper further puts forward the concept of the feasible region for thermal storage and release, offers the calculation method of reserve capacity for thermal storage electric boiler, and verifies the validity of the method through perturbation calculating example. It analyzes the short-term reserve capacity theoretically provided and the renewable energy consumption added to the power grid after accessing to a lot of thermal storage electric boilers based on actual planning data of a province, and finally carries out the simulation discuss regarding the influence of the peak regulation strategy, thermal storage tank capacity, time scale of involving in the reserve market, the expected thermal storage capacity of the next day stated in the reserve contract and other factors on the reserve capacity of thermal storage electric boiler.

\section{Modelling for the heating system of thermoelectric decoupling thermal storage electric boiler}

\subsection{Analysis on operation mode}

For the pure electric boiler heating system, the electric power can only be set as per the operating mode of "fixing heat based on power", and the electricity needs cannot be adjusted due to the rigidity. After installing a thermal storage tank, the electric power and thermal load of electric boiler are decoupled, and the load of electric boiler is transformed into flexible load from the rigid load because of the additional power provided by the thermal storage tank.

Considering the above changes in the above operation mode, the structure of heating system for the thermoelectric decoupling thermal storage electric boiler is shown in Fig.1, which consists of heat source (electric boiler), geothermal reservoir (thermal storage tank), heat supply network (heat exchange station, heat distribution network), thermal load (heat consumer), and the following simplification or assumption is introduced.
1) The equivalent thermal load $D_{H}$ is used to indicate total load of heat consumer, including the heat distribution network loss;

2) The heat transfer loss among electric boiler, thermal storage tank and heat exchange station is negligible.

3) The heat loss of thermal storage tank through tank wall within the short dispatching cycle (e.g. 1 day) is less than $0.7 \%$ of total thermal storage capacity [16], and such heat loss in the model is negligible.

4) Assuming that all the thermal storage electric boilers discussed in this paper are transformed from the pure electric boiler through thermal storage, therefore, the rated thermal power of electric boiler will not be less than the maximum thermal load.

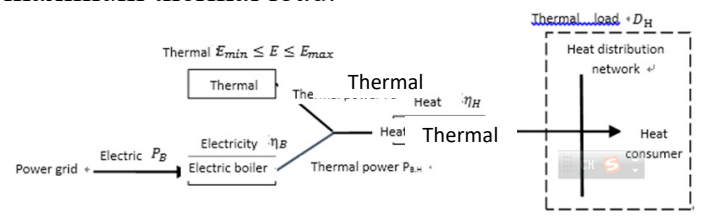

Fig.1. Adequacy modelling of a thermal storage electric boiler based on the heating system.

The model in Fig.1 involves the following equality constraints and inequality constraints.

1) Equality constraint:

Electrical and thermal power balance:

$$
P_{B . H}(t)=P_{B}(t) * \eta_{B}
$$

Internal thermal power balance of system:

$$
P_{B . H}(t)-P_{S}(t)=D_{H}(t) / \eta_{H}
$$

Thermal energy balance of thermal storage tank:

$$
E\left(t_{j}\right)=E\left(t_{i}\right)+\int_{t_{i}}^{t_{j}} P_{S}(t) d t
$$

Wherein: $P_{B}(t), P_{B . H}(t) \eta_{B}$ indicate the electric and thermal power of electric boiler; $\eta_{B}, \eta_{H}$ indicate the electricity heat transfer efficacy and heating efficiency of heat exchange station; $P_{S}(t)$ indicates the thermal power of thermal storage tank (when $P_{S}(t)>0$, the thermal storage tank stores heat, when $P_{S}(t)<0$, the thermal storage tank releases heat); $D_{H}(\mathrm{t})$ indicates the sum of the thermal load loss of heat distribution network; $E(t)$ indicates the thermal energy of thermal storage tank.

2) Inequality constraint:

Electric power limit of electric boiler:

$$
0 \leq P_{B}(t) \leq P_{B . \max }
$$

Thermal power limit of thermal storage tank:

$$
-P_{S . \max } \leq P_{S}(t) \leq P_{S . \max }
$$

Thermal storage capacity limit of thermal storage tank:

$$
E_{S . \min } \leq E(t) \leq E_{S . \max }
$$

Wherein: $P_{B . \max } P_{S . \max }$ indicate the maximum electric power of electric boiler and thermal storage tank; $E_{S . m i n}, E_{S . m a x}$ indicate the minimum and maximum thermal storage capacity of thermal storage tank.

According to the assumption in this paper, the rated thermal power $P_{\text {B.H.max }}$ of electric boiler shall not be less than the maximum thermal load, denoted by Formula (7).

$$
P_{\text {B.H.max }} \geq \max \left(D_{H}(t)\right)
$$




\section{Assessment on the ability of the thermoelectric decoupling thermal storage electric boiler for involving in operation reserve}

\subsection{Restricting factors of reserve capacity}

The influencing factors of thermal storage and release peak regulation and reserve strategy include: electric power of electric boiler, the maximum thermal storage and release power, thermal storage capacity of thermal storage tank, thermal load curve, current thermal storage and release boiler power, which can be classified into heat and power. The heat and power boundary decide the reserve capacity of thermal storage electric boiler.

\subsubsection{Heat boundary}

The heat boundary is derived from the sum of the maximum $E_{S . \max } /$ minimum $E_{S . \min }$ capacity limits of the thermal storage tank. However, it will be transmitted forward and backward within the whole dispatching cycle due to the constraints of power limit and three balances, and then compresses the thermal storage flexible dispatching space of other time periods. In case the heating service provider just dispatches according to the maximum/minimum thermal storage capacity limit, the violation may occur, and the reserve electricity commitment may not be realized, and the up-reserve and down-reserve capacity for power grid cannot be guaranteed.

\subsubsection{Power boundary}

The power boundary is based on thermal power balance and decided by the power limit of electric boiler and thermal storage tank. When the thermal load is fixed, increasing the thermal power $P_{S}(t)$ of thermal storage tank is equivalent to decreasing the power $P_{B}(t)$ of electric boiler, vice versa. But when reaching the electric power limit of electric boiler and the thermal power limit of thermal storage tank, the above adjustment process cannot be continued. Thus, the up-reserve and downreserve capacity of the time periods declared by the heating service provider shall fall within the adjustment range.

\subsection{Feasible region}

Section 3.2 shows that heat boundary and power boundary enclose a flexible dispatching space of thermal storage electric boiler, which constitutes the forming basis of reserve capacity. The literature [17] puts forwards the concept of feasible charging region with regard to charging characteristics of electrical vehicles: The wider the feasible region is, the larger the power and electricity difference of the feasible charging routes between the starting point and ending point is, and the stronger the dispatching flexibility is. On this basis, the following text puts forwards the concept of feasible region for thermal storage and release, as shown in Fig.2.

Fig. 2 elaborates the concept of feasible region form the time-thermal storage capacity plane, and time-electric power plane. The dispatching of thermal storage electric boiler starts from $\left(t_{\text {start }}, E_{\text {start }}\right)$, can end in any point of the range from $\left(t_{\text {exp }}, \underline{E}_{\text {exp }}\right)$ to $\left(t_{\text {exp }}, \bar{E}_{\text {exp }}\right)$, $\bar{E}_{\text {exp }}, \underline{E}_{\text {exp }} t_{\text {exp }}$ are the upper and lower boundaries of the thermal storage capacity expected in the time. The area enclosed by all the feasible strategy routes, including the normal peak regulation strategy (indicated by the dotdashed line route in Fig.2) is called the feasible region of thermal storage and release.

Taking $\left(t_{i}, t_{j}\right)$ time period as an example, the power $P_{i}$ and electricity $E_{i}$ of time $t_{i}$ is decided by the peak regulation strategy of the front segment. The timevarying characteristics of the thermal load within the time period $\left(t_{i}, t_{j}\right)$ are frozen; the boundary of the feasible region can be decided by the "feasible zone" of time $t_{j}$. Formula (3) correlates the states of front and back time periods, so we should consider the forward recurrence (from front to back) and reverse recurrence (from back to front) when determining the zone. The recurrences are conducted to probe the ultimate power regulation quantity on the condition that the power and heat do not exceed the limits in the time period. The up and down power/heat regulation quantities correspond to the up and down reserve feasible region.

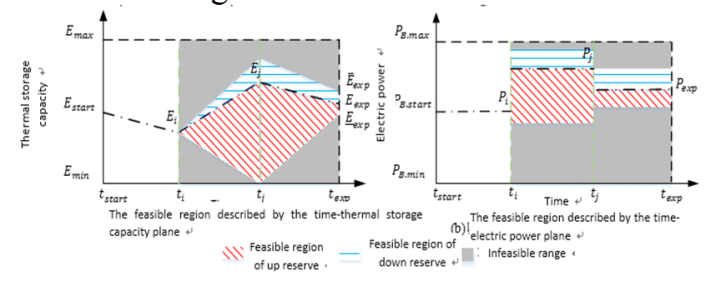

Fig.2. Feasible region of thermal storage and release.

To quantify, we can discretize the timer shaft, divide the above regulating cycle into $n$ isometric time periods (time length of time period $\Delta t$ ), froze the time-varying characteristics within the period, and indicate the discretized period by sequence $k_{i}$. Formula (8) and Formula (9) give the computing methods of "thermal storage capacity feasible zone" for the time $k_{i}$.

$$
\begin{aligned}
& E_{\text {min }}\left(k_{i}\right)=\max \left(E\left(k_{i-1}\right)-\Delta E_{G}\left(k_{i}\right), E_{\text {min }}\left(k_{i+1}\right)-\right. \\
& \left.\Delta E_{L}\left(k_{i}\right), E_{S \cdot \min }\right) \\
& E_{\text {max }}\left(k_{i}\right)=\min \left(E\left(k_{i-1}\right)+\Delta E_{L}\left(k_{i}\right), E_{\text {max }}\left(k_{i+1}\right)+\right. \\
& \left.\Delta E_{G}\left(k_{i}\right), E_{S . \max }\right) \\
& \Delta E_{G}\left(k_{i}\right)=P_{G . \max }\left(k_{i-1}\right) \Delta t \\
& \Delta E_{L}\left(k_{i}\right)=P_{L . \max }\left(k_{i-1}\right) \Delta t \\
& E_{\text {min }}\left(k_{n}\right)=\underline{E}_{\text {exp }} \\
& E_{\text {max }}\left(k_{n}\right)=\bar{E}_{\text {exp }}
\end{aligned}
$$

Wherein, $E_{\max }\left(k_{i}\right), E_{\min }\left(k_{i}\right)$ give the upper and lower boundary of the "feasible zone" for the time $k_{i}, \Delta E_{L}\left(k_{i}\right)$ and $\Delta E_{G}\left(k_{i}\right)$ mean thermal storage capacity and thermal release capacity of the time. 
$k_{i} P_{\text {L.max }}\left(k_{i}\right)$ and $P_{G . \max }\left(k_{i}\right)$ mean the maximum thermal storage, thermal release power for the time $k_{i}$, and they are determined by Formula (14) and

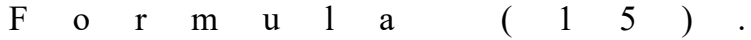

$$
\begin{aligned}
& P_{\text {L.max }}\left(k_{i}\right)=\min \left(P_{\text {B.H.max }}-D_{H}\left(k_{i}\right), P_{\text {S.max }}\right) \\
& P_{G . \max }\left(k_{i}\right)=\max \left(D_{H}\left(k_{i}\right), P_{S . \max }\right)
\end{aligned}
$$

Therefore, the "feasible zone for thermal storage capacity" of the time can be calculated according to Formula (8) and Formula (9) on the premise of giving the peak regulation strategy; The up and down envelope lines of the above zone enclose the feasible region of thermal storage and release; The reserve capacity of thermal storage electric boiler can be easily calculated according to the feasible region.

\subsection{Calculation method for reserve capacity of thermal storage electric boiler}

Formula (16) and Formula (17) give the methods of calculating the up and down reserve capacity of thermal storage electric boiler through the feasible region of thermal storage and release, respectively:

$$
\begin{aligned}
& R_{B u}\left(k_{i}\right)=\min \left(\frac{E\left(k_{i}\right)-E_{\min }\left(k_{i+1}\right)}{\Delta t \cdot \eta_{B}}, P_{B}\left(k_{i}\right)-\right. \\
& \left.P_{B \cdot \min }\left(k_{i+1}\right)\right) \\
& R_{B \mathrm{~d}}\left(k_{i}\right)=\min \left(\frac{E_{\max }\left(k_{i+1}\right)-E\left(k_{i}\right)}{\Delta t \cdot \eta_{B}}, P_{B \cdot \max }\left(k_{i+1}\right)-\right. \\
& \left.P_{B}\left(k_{i}\right)\right)
\end{aligned}
$$

Wherein: $P_{B \cdot \min }\left(k_{i}\right)$ and $P_{B \cdot \max }\left(k_{i}\right)$ mean the minimum and maximum electric power of the time after totaling the rated power and thermal equilibrium constraints of electric boiler/thermal storage tank, which are given by Formula (18) and Formula (19). $k_{i} E\left(k_{i}\right)$ indicates the thermal storage capacity of thermal storage tank for the time, as shown in Formula (20), it is the discrete version of Formula (3).

$$
\begin{aligned}
P_{B . \max }\left(k_{i}\right) & =\left(P_{L . \max }\left(k_{i}\right)+D_{H}\left(k_{i}\right) / \eta_{H}\right) / \eta_{B} \\
P_{B . \min }\left(k_{i}\right) & =\left(-P_{G . \max }\left(k_{i}\right)+D_{H}\left(k_{i}\right) / \eta_{H}\right) / \eta_{B} \\
E\left(k_{i}\right) & =E\left(k_{i-1}\right)+P_{S}\left(k_{i}\right) \cdot \Delta t
\end{aligned}
$$

Formula (20) is the recursion formula of $E\left(k_{i}\right)$, and the electricity state $E\left(k_{0}\right)$ is at the starting point is $E_{\text {start }}$ in Fig.2.

The simulation verification is performed based on the model stated in Section 1 of this paper, and the results show that: Setting the power adjustment quantity of the Dispatch Instruction beyond the calculation structure of Formula (18-19) will result in heat loss load or overload immediately; in order to avoid heat balance, the only response is lack of control. Therefore, the results given by the method in this section are theoretical limits of up/down-regulation reserve capacity for thermoelectric decoupling thermal storage electric boiler.

\section{Simulation analysis}

The following text realizes the algorithm in Section 2 based on the large energy dynamic simulation platform of NARI, and carries out the simulation analysis on the influence of the large-scale installation of thermal storage electric boiler cluster in a province or clean heating engineering on the adequacy of power grid by combining the actual data.

\subsection{Setting of simulation parameters}

This paper relies on the clean heating engineering, and shows the technical parameters of thermal storage electric boiler cluster in Attached Tables A1 and A2. It sets 3 electricity strategies through simulation, as shown in Attached Table A3, and compares the influence of different strategy on the reserve capacity of thermal storage electric boiler.

\subsection{Analysis on the short-term reserve involvement and renewable energy consumption effect}

The scale of electric heating of 2030 is predicted (the predication method and results are shown in Attached Figure A1) according to the rules and based on the planning report of the clean heating of a province, and the average thermal storage duration is set as $3 \mathrm{~h}$, then the total thermal storage capacity of the province in 2030 is up to $4.5 \mathrm{GWh}$. Other parameter settings can be found in the Attached Table A1.

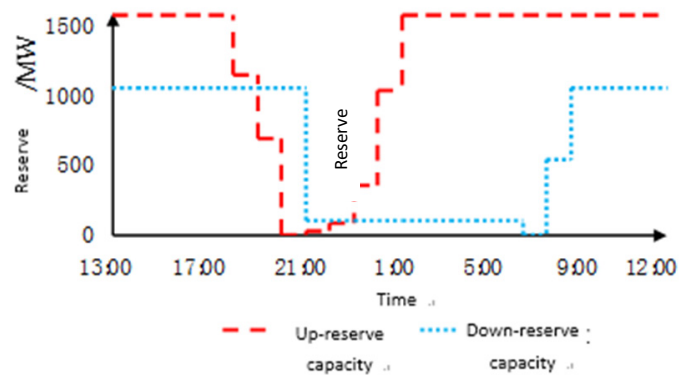

Fig.3. Predicted $1 \mathrm{~h}$ reserve capacity of the provincial thermal storage electric boiler cluster in a day of the 2030's heating season.

Fig.3 gives the potential $1 \mathrm{~h}$ reserve capacity of provincial thermal storage electric boiler cluster in heating season under the typical peak regulation operation mode. The peak regulation method (as shown in Figure 6) is mainly characterized by storing heat at night, and absorbing the excess wind power in the time period to the largest extent. The thermal storage tank is emptied in 20:00, and the heat consumption peak is reached between 17:00 and 24:00 at night. So during the time period, the electric power of the boiler is larger, more rigid, and cannot be down regulated. Both up and down- 
regulation reserve capacity is the lowest throughout the day. At 1:00, the up-regulation reserve capacity recovers gradually; 24:00-8:00 is the off-peak period of thermal load. However, the electric boiler stores heat in high power due to the peak regulation operation mode, and the up-regulation space of power is insufficient. Therefore, the down-regulation reserve capacity still remains low (about 107MW in the figure), and recovers gradually until the thermal release time period.

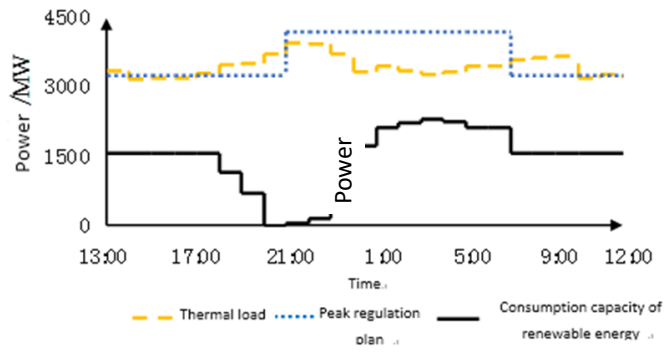

Fig.4. Predicted renewable energy generation supported by the thermal storage electric boilers in 2030.

Fig.4 further calculates the effect (maximum theoretical value) of promoting the consumption of renewable energy for the provincial thermal storage electric boiler cluster through conducting the peak regulation operation and providing reserve for the power grid. The value is indicated by the solid line in Fig.4, which not only considers the electricity consumed by thermal storage capacity peak regulation, but also considers the electricity consumption added to full play the reserve capacity of thermal storage electric boiler cluster. Therefore, it is the sum of wind curtailment power of thermal storage electric boiler cluster extra consumed due to peak regulation operation and the up-regulation reserve provided to power grid. The tests show that, the renewable energy generation consumed (supported) by the provincial thermal storage electric boiler cluster in 1 day can reach $34.9 \mathrm{GWh}$.

Next, this paper further analyzes the influence of the peak regulation electricity strategy, capacity of thermal storage tank, setting for the expected thermal storage capacity in contract, setting for time scale of reserve market and other factors on the above reserve capacity and renewable energy consumption promotion.

\subsection{Analysis on the parametric sensitivity influencing the reserve capacity}

\subsubsection{Influence of peak regulation strategy}

The peak regulation strategy formulated for thermal storage electric boiler will have a significant impact on the reserve capacity. Fig.7 shows that the simulation result of $1 \mathrm{~h}$ reserve capacity for thermal storage electric boiler cluster under the electricity utilization plan determined by Strategies 1-3 I (refer to Attached Table A3). In Strategy 1 , the thermal storage tank is not charged or discharged, and the electric power only fluctuates as the thermal load changes, so there is only up-regulation reserve. In Strategy 2 , the thermal storage tank is considered, and the peak is regulated along the solid line in the figure, so there are both up and down-regulation reserve capacity. Strategy 3 further tracks the wind curtailment power and formulates the peak regulation plan (namely, storing heat in the maximum thermal power at the wind curtailment time period). Compared with Strategy 2, additional 73.6MWh wind curtailment electricity is consumed, and the downregulation reserve capacity is improved obviously when the up-regulation reserve capacity keeps unchanged.

In addition, Figure 7 shows: the real-time up-regulation reserve capacity will be restrained when the thermal storage tank is emptied. Therefore, thermal storage tank should not be emptied at the time periods when the power grid is liable to up-regulation power gap; on the contrary, the down-regulation reserve capacity will be restrained when the thermal storage tank is fully stored.

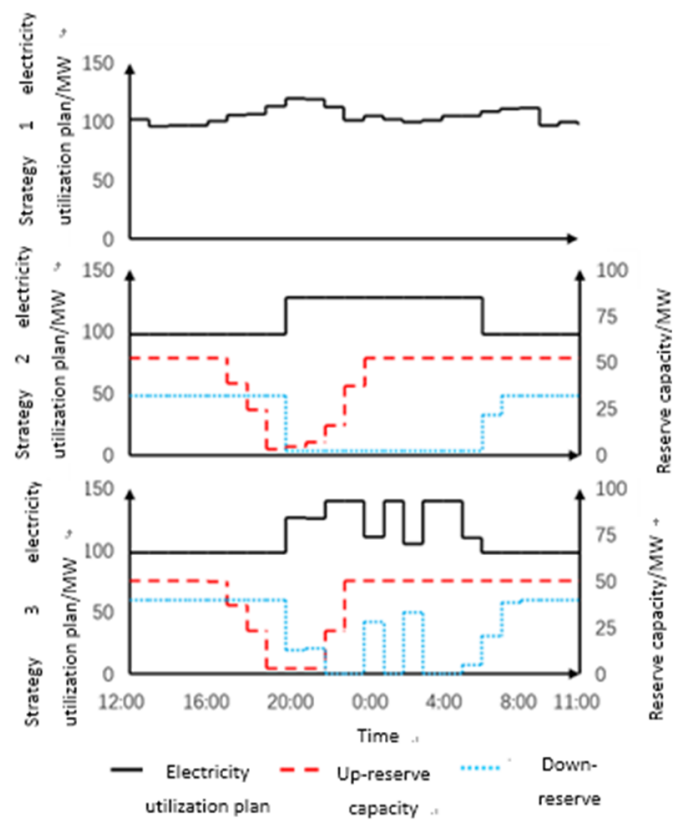

Fig.5. Reserve capacity generated by the thermal storage electric boiler cluster under different strategies.

\subsubsection{Effect of thermal storage tank capacity}

The effect of thermal storage tank capacity on short-term reserve capacity is shown in Fig.6. In the simulation, the parameters of thermal storage electric boilers are derived from Attached Table A2, and Strategy 2 in Section 3.3.1 is used as the electricity utilization plan. In the comparison, the initial thermal storage capacity is equal.

As shown in the Fig., the depth peak regulation capacity increases with the increase of the thermal storage capacity/volume ratio $\left(E_{S . \max } / P_{S \text {.max }}\right)$. At the same time, the drop section width of the up-regulation reserve capacity gradually narrows, and the dynamic characteristics continue to improve; the down-regulation reserve capacity constantly improves, but it is limited by power constraints. The greater the peak regulation depth is, the lower the down-regulation reserve capacity in the corresponding time period is. 


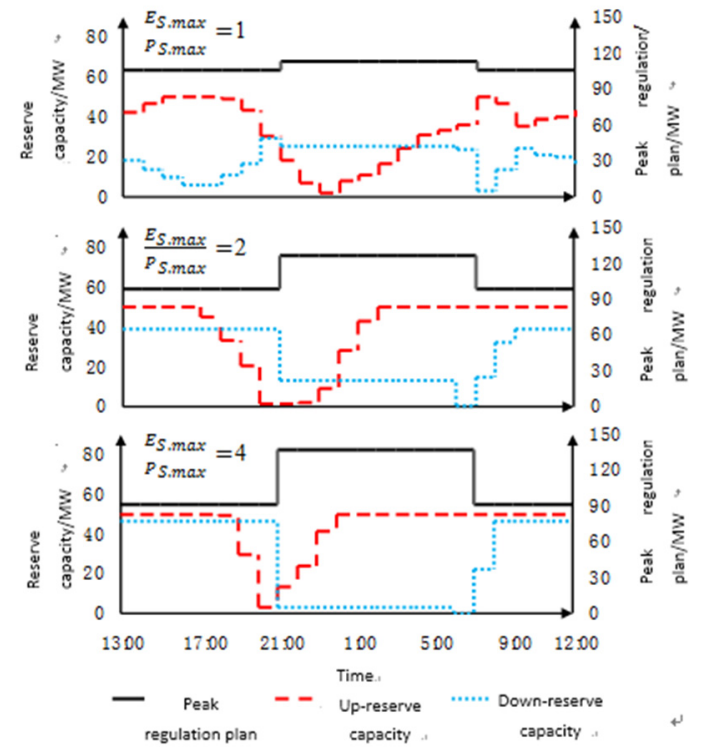

Fig.6. Reserve capability generated by the thermal storage electric boiler cluster under different tank capacity.

\subsubsection{Capacity differences in different market scales}

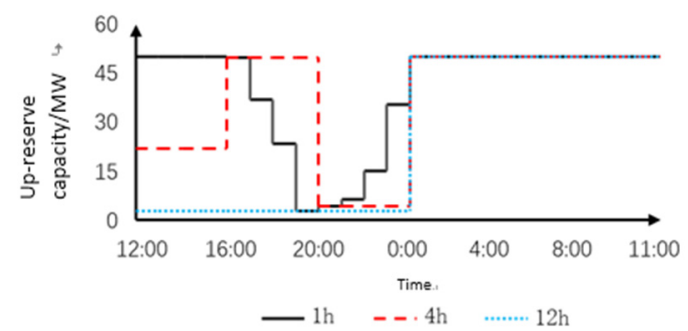

Fig.7. Maximum up-reserve capacity of thermal storage electric boiler cluster at different time scales.

The reserve markets at different time scales determine the contract term of the reserve service of thermal storage electric boilers. The reserve capacity of thermal storage electric boilers is mainly affected by the real-time thermal storage capacity. Due to different time scales, the declarable reserve capacity of thermal storage electric boilers at different time scales should be the lowest reserve capacity in that time period. Taking the up-reserve in Strategy 2 as an example, the declarable up-reserve capacity at different time scales of $1 \mathrm{~h}, 4 \mathrm{~h}$ and $6 \mathrm{~h}$ can be seen in Fig.7, and the simulation time is from 12:00 today to 12:00 tomorrow. The black solid line, the red dotted line and the blue dotted line indicate $1 \mathrm{~h}$ reserve capacity, $4 \mathrm{~h}$ reserve capacity and $6 \mathrm{~h}$ reserve capacity, respectively. It can be seen that the smaller the time scale of involving in the reserve market is, the larger the declarable reserve capacity of thermal storage electric boilers is.

\subsubsection{Effect of expected thermal storage capacity}

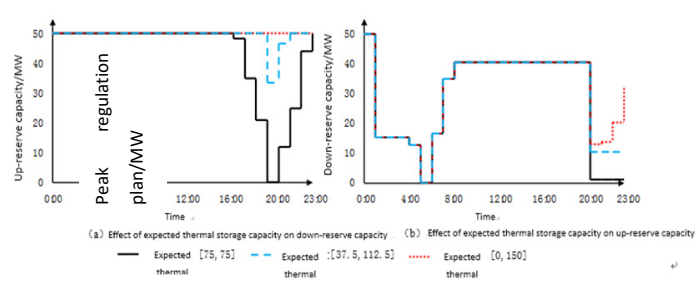

Fig.8. The influence of the expected thermal storage capacity on the reserve capacity of the thermal storage electric boiler cluster within $1 \mathrm{~h}$ high availability.

The expected thermal storage capacity is the thermal storage of thermal storage tank that we look forward to at the ending time of our dispatching plan. The expected thermal storage capacity determines the thermal storage and release strategy, and influences the peak regulation plan. What is shown in Fig.8 is the simulation result of the expected thermal storage capacity on the reserve capacity of the thermal storage electric boiler cluster within $1 \mathrm{~h}$ high availability. The parameters of the calculating example are seen at the Attached Table A2, $E_{S \text {. } \max }=150 \mathrm{MWh}$, $E_{S . \max }=75 \mathrm{MWh}$, and the electricity utilization plan is seen Strategy 2 from the Attached Table A3.

In the first half, the up-reserve capacity is the same as down-reserve capacity, which caused by the very same thermal storage feasible region. In the latter half, because the expected thermal storage capacity was different at 24:00, the thermal storage feasible region changed. The larger the evaluation of the expected thermal storage capacity, the richer of the up-reserve and down-reserve capacity is. It can thus be seen that the expected thermal storage capacity affects both the reserve capacity and the thermal storage and release capacity in a certain time period, then affects the profits of heat suppliers.

\section{Conclusion}

This paper is aimed at the problems caused when the thermoelectric decoupling thermal storage electric boiler joins in the power grid reserve processes. Firstly, it is made that the energy balance model of the thermal storage electric boiler heating system, and provided that the concept of thermal storage feasible region. Secondly, according to the above the concept and the model, it is provided that the calculation method of thermal storage electric boiler reserve capacity under the given peak regulation strategy. Finally, on the basis of the actual power grid planning data, it is analyzed that the reserve capacity of the large scale thermal storage electric boiler cluster and the maximum effect generated to promote the renewable energy consumption when system reserve capacity is short; and that the influence of many factors-the peak regulation strategy, the thermal storage tank capacity, the time scale of the ready reserve market, the range setting of the expected thermal storage capacity on the next day in the reserve deal and so on -- on the shortterm reserve capacity of the thermoelectric decoupling thermal storage electric boiler. The study of follow-up plans includes: the contradiction optimization between reserve demands and power utilization when avoid the peak hour, and the reasonable selection of thermal storage 
capacity to equilibrate the economic efficiency and the power grid flexibility.

This research work was funded by the China State Grid Corporation the Science and Technology project of "The Active Support of Power Grid to Energy Transition of Clean Energyrich Region: A Case Study of Qinghai Province".

\section{References}

1. SHU Yinbiao. Accelerate the construction of a strong smart grid and Promote the energy production and consumption revolution[J]. Science and Technology Industry of China, 2018, No.347(5):12.

2. ZHANG N, KANG C, XIA Q, et al. Modeling Conditional Forecast Error for Wind Power in Generation Scheduling[J]. IEEE Transactions on Power Systems, 2014, 29(3):1316-1324.

3. JIANG Y, CHEN X, KUN Y U, et al. Short-term wind power forecasting using hybrid method based on enhanced boosting algorithm $[\mathrm{J}]$. Journal of Modern Power Systems and Clean Energy, 2017, 5(1):126-133.

4. Energy Observer. Can thermal power flexibility be able to break the contradiction between wind and fire

[EB/OL] http://www.chinanengyuan.com/news/109222.html. 2017-05-31/2019-07-26.

5. CUI Yang, CHEN Zhi, YAN Gangui, et al. Coordinated Wind Power Accommodating Dispatch Model Based on Electric Boiler and CHP With Thermal Energy Storage $[\mathrm{J}]$. Proceedings of the CSEE, 2016, 36(15):4072-4080.

6. Ling C , Ge Q, Lu J , et al. Research on control strategy of electric heat storage boiler based on multi-agent $[\mathrm{C}] / /$ Power \& Renewable Energy. IEEE, 2017.

7. DENG Tuoyu, TIAN Liang, LIU Jizhen. Spatial and Temporal Multiscale Analysis on Energy Storage in Heat Supply Units' Boiler and Heat Supply Nets[J]. Proceedings of the CSEE, 2017, 37(2):599-605.

8. HUANG X, XU Z, SUN Y, et al. Heat and power load dispatching considering energy storage of district heating system and electric boilers[J]. Journal of Modern Power Systems and Clean Energy, 2018.

9. LYU Quan,JIANG Hao,CHEN Tianyou, et al.Wind Power Accommodation by Combined Heat and
Power Plant with Electric Boiler and Its National Economic Evaluation[J].Automation of Electric Power Systems,2014,38(1):6-12. DOI: 10.7500/ AEPS201206124.

10. LI Jiajia, HU Linxian. Research on Accommodation Scheme of Curtailed Wind Power Based on PeakShaving Electric Boiler in Secondary Heat Supply Network[J]. Power System Technology, 2015, 39(11):3286-3291.

11. GUO Fenghui, HU Linxian, ZHOU Shengyu. Dispatching Model of Wind Power Accom-modation Based on Heat Storage Electric Boiler for Peak-load Regulation in Secondary Heat Supply Network[J].Automation of Electric Power Systems ,2018,42(19):50-56.

DOI: 10.7500/AEPS20180130009.

12. FANG Jinyu, SONG Ziqiu, HAN Xiaojuan, et al. Study on Wind Power Consumption Method Using Energy Storage Technology to Coordinate Heat Storage Electric Boilers[J]. Electrical and Energy Management Technology, 2017(13):16-21.

13. LI Junhui, XING Zhitong, XING Jin, et al. Design of Optimized Planning Platform of Electric Boiler with Heat Storage to Enhance Wind Power Consumption.[J] Acta Energiae Solaris Sinica, 2017(13):16-21.

14. WANG Zhibin, GU Bowen, ZU Guangxin, et al. Research on the operation mode of regenerative electric boiler system based on multi-wind bidding $[\mathrm{J}]$. Heilongjiang Electric Power, 2018, 40(04):70-74.

15. LIU Jiantao, ZHU Bingquan, MA Jingwei, et al. Study on Evaluation Indexes of Spinning Reserve Capacity Considering Reliability in Day-ahead Schedule[J]. Power System Technology, 2019,43(06):2147-2154.

16. CHEN X, KANG C, O'MALLEY $M$, et al. Increasing the Flexibility of Combined Heat and Power for Wind Power Integration in China Modeling and Implications[J]. IEEE Transactions on Power Systems, 2015, 30(4):1848-1857.

17. WU Juai,XUE Yusheng,XIE Dongliang, et al.Evaluation and Simulation Analysis of Reserve Capability for Electric Vehicles[J].Automation of Electric Power Systems,2018,42(13):101-107. DOI: 10.7500/AEPS20180130012. 